\title{
Intracranial Atherosclerosis: Current Understanding and Perspectives
}

\author{
Oh Young Bang \\ Department of Neurology, Samsung Medical Center, Sungkyunkwan University School of Medicine, Seoul, Korea
}

The importance of intracranial atherosclerotic disease (ICAD) as a cause of stroke is underscored as compared to that of extracranial carotid stenosis and nonvalvular atrial fibrillation. Recent large clinical trials of ICAD, which evaluated the effectiveness of anticoagulation and stenting to prevent thromboembolism and restore hemodynamic compromise, failed to reduce major vascular events in patients with ICAD. These trials showed the importance of optimal control of risk factors to reduce major vascular events in these patients. Recent advances in risk factors for ICAD are summarized, together with possible reasons for race-ethnic differences in the prevalence of ICAD. In addition, the failure of the major clinical trials of ICAD may be caused by limitations in the understanding of ICAD. Unlike in patients with extracranial carotid stenosis or atrial fibrillation, stroke associated with ICAD occurs in association with various stroke mechanisms such as in situ thrombotic occlusion, artery-to-artery embolism, hemodynamic insufficiency, and branch occlusion. In clinical trials of ICAD, patients with all these types of ICAD were included. However, treatment effects may differ among the different types of ICAD. Treatment strategies might be selected based on clinical features (including the time after onset) and serologic and neuroimaging biomarkers (including diffusion-weighted image pattern and plaque images). Additional clinical trials considering these features are needed.

Keywords Atherosclerosis; Stroke; Intracranial; Plaque
Correspondence: Oh Young Bang Department of Neurology, Samsung Medical Center, Sungkyunkwan University, 81 Irwon-ro, Gangnam-gu, Seoul 135-710, Korea

Tel: +82-2-3410-3599

Fax: +82-2-3410-1430

E-mail: neuroboy50@naver.com

Received: September 18, 2013

Revised: October 12, 2013

Accepted: October 14, 2013

This study was supported by the Korean Healthcare Technology R\&D Project, Ministry of Health \&t Welfare (A110208).

The authors have no financial conflicts of interest.

\section{Introduction}

The importance of intracranial atherosclerotic disease (ICAD) as a cause of stroke is underscored as compared to that of extracranial carotid stenosis and nonvalvular atrial fibrillation. There have been several studies with long-term follow-up data and randomized clinical trials in extracranial carotid stenosis and nonvalvular atrial fibrillation; the risk of stroke and treatment effects were evaluated separately in both asymptomatic (strokefree) and symptomatic patients. On the contrary, ICAD was not considered or was lumped with extracranial carotid stenosis as an atherosclerotic stroke subtype in most clinical trials ${ }^{1}$ and current stroke guidelines. ${ }^{2}$ However, ICAD differs from extracranial atherosclerotic stroke in many aspects, including risk factors and stroke patterns. ${ }^{3-5}$

Large clinical trials of ICAD have recently evaluated the effectiveness of anticoagulation (the Warfarin Aspirin Symptomatic Intracranial Disease [WASID] trial) and stenting (the Stenting and Aggressive Medical Management for Preventing Recurrent Stroke in Intracranial Stenosis [SAMMPRIS] trial) to prevent thromboembolism and restore hemodynamic compromise, but failed to reduce major vascular events in patients with ICAD. ${ }^{6,7}$ The failure of these trials may be caused by limitations in the current understanding of ICAD. In this review, the vari- 
ous mechanisms of stroke will be discussed because treatment effects may differ among the different types of ICAD. In addition, recent advances in risk factors for ICAD are summarized because the trials drew attention to the importance of recognition and adequate control of risk factors for ICAD.

\section{Epidemiology and natural course of ICAD}

Knowledge of the epidemiology of ICAD is limited. ${ }^{8}$ There have been no data on the prevalence of ICAD in large clinical trials, and data are limited regarding the prevalence of asymptomatic ICAD in the general population. ICAD may be as prevalent as extracranial carotid artery disease. The population-based Rotterdam study has evaluated the prevalence of intracranial internal carotid artery calcification, a marker of intracranial atherosclerosis which was observed in over $80 \%$ of older, white subjects. ${ }^{9}$ In addition, a transcranial Doppler study showed that the prevalence of asymptomatic middle cerebral artery (MCA) stenosis ranged from 7.2\%-30\% among Asian patients who had vascular risk factors without a history of stroke or TIA..$^{10}$ ICAD causes 30\%-50\% of strokes in Asia, ${ }^{11}$ and 8\%-10\% of strokes in North America, ${ }^{12}$ making it one of the most common causes of stroke worldwide. ${ }^{13}$

ICAD is more prevalent in Asians than in Westerners; the reason for this is unknown. Possible explanations include inherited susceptibility of intracranial vessels to atherosclerosis, ${ }^{14}$ acquired differences in the prevalence of risk factors, ${ }^{15,16}$ and differential responses to the same risk factors. ${ }^{17,18}$ Lifestyle may play a role in the racial-ethnic differences: the pattern of ischemic stroke is changing in Asian patients. With the westernized lifestyle, the number of extracranial cervical disease is rising. ${ }^{19,20}$ Lastly, it is also possible that patients with adult-onset moyamoya disease (MMD) are misclassified as having ICAD, which may partly explain the high prevalence of intracranial atherosclerosis in Asians. Ring finger 213 (RNF213) was recently identified as the strongest susceptibility gene for MMD in East Asian people by a genome-wide linkage analysis and an exome analysis. ${ }^{21,22}$ The number of patients with MMD was estimated to be more than 53,800 in East Asian populations. ${ }^{23,24}$ The prevalence of MMD has recently increased with more careful consideration of the disease and better diagnostic techniques; ${ }^{25}$ many patients may have been misclassified as having ICAD.

The natural history of asymptomatic vs. symptomatic ICAD differs from that of extracranial carotid disease. Compared to asymptomatic extracranial carotid disease, asymptomatic ICAD has a low risk of stroke in the stenotic arterial territory, while the risk is very high in patients with symptomatic ICAD, especially in patients with clinically significant hemodynamic stenosis, early after stroke. ${ }^{6,26}$ Several clinical and laboratory findings reportedly predict stroke in patients with ICAD. The WASID trial showed that a shorter time from stroke ( $\leq 17$ days), severe stenosis $(\geq 70 \%)$, baseline severe neurological deficits, poorly controlled hypertension, and elevated low-density lipoprotein cholesterol (LDL) levels are independent predictors for recurrence after stroke due to ICAD. ${ }^{27}$ Regardless, progression in stenosis $^{28,29}$ and DWI lesion pattern (subcortico-cortical lesion and multiple lesions ${ }^{30}$ are also associated with recurrent stroke in ICAD.

\section{Phenotypes and high-resolution MRI findings of ICAD}

From single, small subcortical perforator infarctions to multiple cortical infarctions, various radiologic stroke patterns are associated with ICAD. ${ }^{31,32}$ Stroke associated with ICAD occurs in association with various stroke mechanisms such as in situ thrombotic occlusion, artery-to-artery embolism, hemodynamic insufficiency, and branch occlusion (Figure 1). Patients with unstable intracranial plaque may show large territorial lesions via sudden thrombotic occlusion. Artery-to-artery embolism, which commonly causes multiple cortico-subcortical infarcts, can be detected by performing transcranial duplex monitoring. Branch occlusive disease (BOD) is one of the main stroke mechanisms of ICAD, which can be characterized by a milder degree of stenosis ${ }^{33}$ and comma-shaped infarcts extending to the basal surface of the parent artery. ${ }^{34}$

Two major features of intracranial atherosclerosis include: (a) atherosis caused by cholesterol deposition and inflammation, and (b) sclerosis secondary to endothelial dysfunction, leading to arterial stiffness. ${ }^{35}$ Risk factors and vessel wall pathology may differ between the two. An autopsy study showed that risk factors differed between those with intracranial-plaque vs. plaquenegative stenosis. ${ }^{36}$ Older age, male gender, and diabetes were commonly associated with the presence of intracranial plaques and stenoses. Interestingly, history of myocardial infarct was an independent risk factor for intracranial plaque but not for plaquenegative stenosis, whereas stroke history was associated with stenosis but not plaque.

Recently, high-resolution MR techniques have been used to evaluate the frequency and role of intracranial artery plaques in living patients with stroke. Patients with symptomatic (vs. asymptomatic) and non-BOD type (vs. BOD) ICAD had characteristic changes in (a) the wall area (larger plaques), (b) plaque signals (eccentric enhancement and heterogeneous signal intensity suggesting unstable plaque), and (c) remodeling patterns (positive remodeling suggesting outward expansion of the 


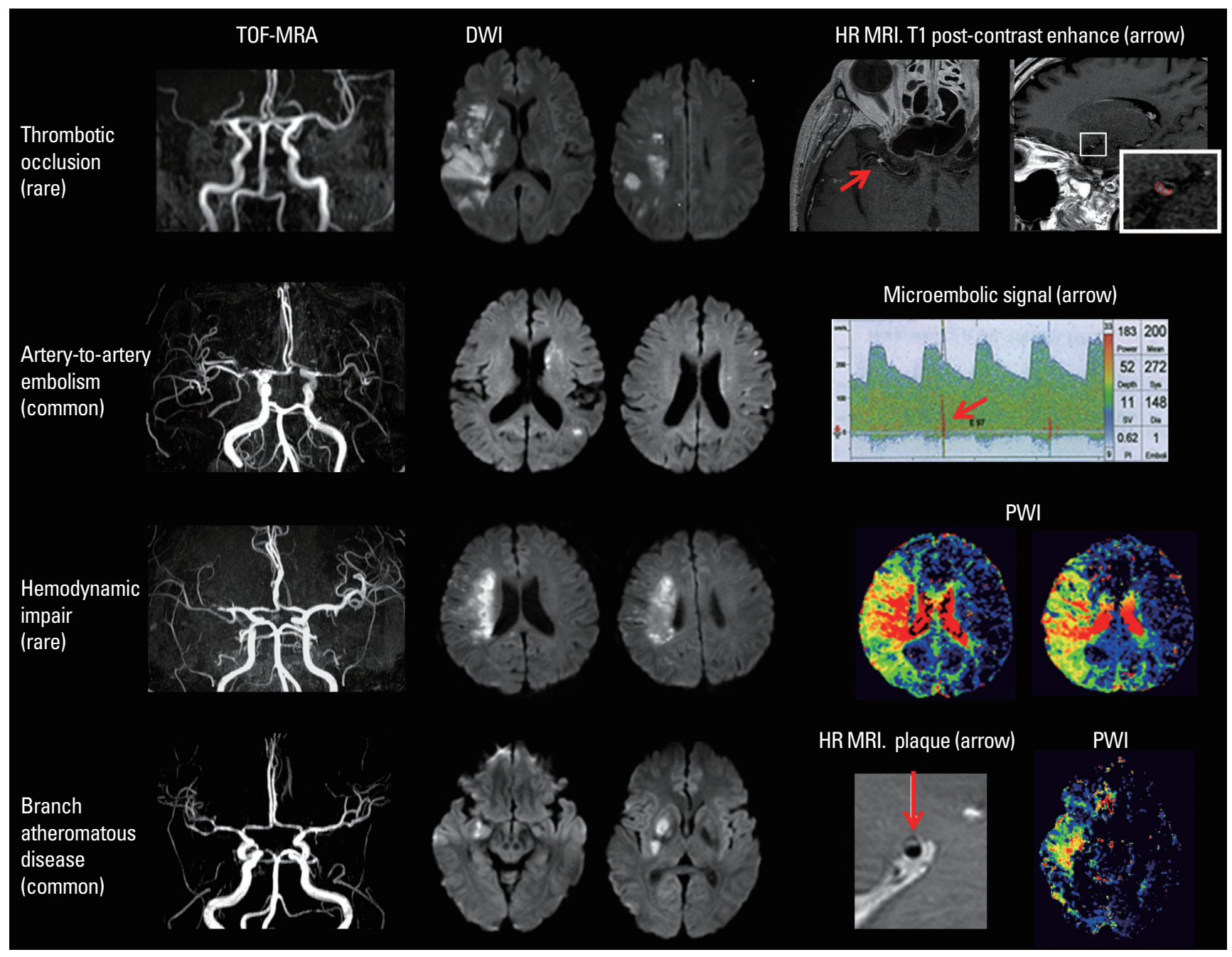

Figure 1. Mechanisms of stroke in patients with ICAD. (A) Thrombotic occlusion is a rare phenotype of ICAD. Magnetic resonance angiography (MRA) shows in situ thrombotic occlusion at the site of stenotic plaque. DWI shows territorial infarcts by severe hemodynamic compromise and embolic infarcts on the cortex. High-resolution MRI can show vulnerable plaque on intracranial vessels. (B) Artery-to-artery embolism is one of common phenotypes of ICAD. Artery-to-artery embolism is usually associated with a severe degree of intracranial stenosis, and transcranial Doppler ultrasonography can detect symptomatic or asymptomatic embolism during microembolic signal monitoring. DWI shows small, scattered, cortical embolic infarcts. (C) Hemodynamic impairment is another phenotype of ICAD. This phenotype is usually associated with a severe stenosis and a marked hemodynamic compromise, as seen on a perfusion-weighted image (PWI). DWI typically shows borderzone-type infarcts, and infarct growth is common with clinical deterioration. (D) Branch occlusive disease is a common phenotype of ICAD. This phenotype is often misclassified as small arterial disease due to a mild degree of stenosis on MRA, small deep infarcts on DWI, and relatively small perfusion defects. High-resolution $\mathrm{MRI}$ can reveal plaque without stenosis near the orifices of penetrating arteries.

vessel wall)..$^{37-39}$ On the contrary, superiorly located MCA plaques (near to the orifices of penetrating arteries) are associated with BOD-type ICAD. ${ }^{40,41}$

\section{Results of major clinical trials of ICAD}

There are three therapeutic strategies for ICAD: (a) antithrombotics, (b) intervention to prevent thromboembolism and restore blood flow, and (c) identification and control of risk factors. Most studies have focused on the prevention of thromboembolism, including the WASID trial ${ }^{6}$ and the FISS-tris tri$\mathrm{al}^{42}$ which compared the benefit of anticoagulants vs. aspirin, and the recent SAMMPRIS wingspan stenting trial. ${ }^{7}$ However, no studies have been conducted to evaluate the effect of risk factor control in preventing stroke recurrence in ICAD patients.

Both oral and parenteral anticoagulation failed to show beneficial effects in preventing recurrent stroke in patients with ICAD. ${ }^{6,43}$ The WASID trial has shown that warfarin and aspirin were equally effective for preventing stroke or vascular death. ${ }^{6}$ In fact, both warfarin and aspirin were ineffective, given the high event rates in both arms. Risk factors were poorly controlled in the WASID trial. The most important findings in the WASID trial were related to the importance of controlling risk factors to reduce major vascular events in ICAD patients. Patients were 
poorly controlled in terms of mean systolic blood pressure and LDL level. Although this study did not examine the effect of risk factor control in symptomatic ICAD patients, the post hoc analyses suggest that lowering blood pressure and LDL may reduce major vascular events in ICAD patients. ${ }^{44}$

Thus, in the following SAMMPRIS trial, aggressive risk factor management was performed, targeting LDL below $70 \mathrm{mg} /$ $\mathrm{dL}$, systolic blood pressure below $140 \mathrm{mmHg}$, and a comprehensive lifestyle modification program. ${ }^{7}$ In the SAMMPRIS trial, the rate of stroke or death within the first 30 days was $14 \%$ in the Wingspan stenting arm vs. $5.8 \%$ in the aggressive medical management arm. The SAMMPRIS investigators stopped enrollment prematurely due to futility; the trend was not changed until 1 year. The higher stroke rate in the stenting arm than in aggressive medical management arm in SAMMPRIS was driven by several factors such as (a) inclusion of patients with perforator syndrome, a smaller vessel size, diffuse stenoses (oversizing of devices) in patients with high peri-procedural stroke risk (ischemic or hemorrhagic), (b) procedural considerations of stringent blood pressure control, general anesthesia, operator experience, etc., and (c) most importantly, improved medical treatment including high-dose statin therapy. ${ }^{45,46} \mathrm{It}$ is interesting that the rate of stroke or death in the aggressive medical management arm was substantially lower than in historical (WASID) controls. This highlights the importance of aggressive con- trol of risk factors. As shown in Table 1, the recurrence rate of stroke decreased in the recent clinical trials of ICAD. This is in line with the carotid intervention (endarterectomy) trials, which showed that in patients with asymptomatic carotid stenosis the stroke risk in the control group has lowered during the last 30 years with aggressive medical treatment including risk factor control. ${ }^{47}$ The annual risk rate of stroke in the control group of the recent trials has lowered even more than that in the carotid intervention group. Just as carotid endarterectomy is indicated only for high risk (annual stroke risk $>1 \%$ ) patients with asymptomatic carotid stenosis, intracranial stenting should be reserved for high risk patients/lesions to prevent disabling stroke refractory to a comprehensive regimen of medical therapy.

\section{Control of risk factors for ICAD}

Therefore, it is important to control vascular risk factors aggressively, and to find out risk factors more specific to ICAD. Until now, risk factors for ICAD of various conditions have been reported, from risk factors associated with asymptomatic ICAD to risk factors for stroke recurrence (Table 2). Classic risk factors for stroke such as hypertension, diabetes, and lipid disorders, are commonly associated with these conditions. However, many studies showed that these classic risk factors are not major determinants of the location of extracranial or intracranial ath-

Table 1. Low rate of stroke in the recent clinical trials of ICAD

\begin{tabular}{|c|c|c|c|}
\hline & WASID, 2005 (Anticoagulation) & SAMMPRIS, 2011 (Stenting) & TOSS-2, 2011 (Antiplatelet) \\
\hline Treatment arms & Warfarin $(n=289)$ vs. $A S A(n=280)$ & AMM $(n=227)$ vs. Stenting $(n=224)$ & ASA+Clopiodogrel $(n=225)$ vs. ASA+Cilostazol $(n=232)$ \\
\hline Patients & 50\%-99\% stenosis & 70\%-99\% stenosis & Focal stenosis on MRA \\
\hline Randomization after stroke & $<90$ days (median, 17 days) & $<30$ days (median, 7 days) & $<14$ days \\
\hline Duration of F/U & 1.8 years & 1 year & 7 months \\
\hline Primary end point & $21.8 \%$ vs. $22.1 \%$ & $12.2 \%$ vs. $20.0 \%$ & $4.4 \%$ vs. $6.5 \%$ (clinical events) \\
\hline \multicolumn{4}{|c|}{ Risk factor control (baseline $\rightarrow$ follow up) } \\
\hline Systolic BP & $<140 \mathrm{mmHg}, 55 \rightarrow 53 \%$ & Mean, $147 \rightarrow 135 \mathrm{mmHg}$ & \\
\hline LDL-C & $\begin{array}{c}<100 \mathrm{mg} / \mathrm{dL}, 29 \rightarrow 56 \% \\
<70 \mathrm{mg} / \mathrm{dL}, 9 \rightarrow 10 \%\end{array}$ & Mean, $98 \rightarrow 73$ mg/dL & Mean, $121 \rightarrow 95 \mathrm{mg} / \mathrm{dL}$ \\
\hline HDL-C & $>40 \mathrm{mg} / \mathrm{dL}, 64 \rightarrow 63 \%$ & Mean, $39 \rightarrow 42 \mathrm{mg} / \mathrm{dL}$ & Mean, $43 \rightarrow 49 \mathrm{mg} / \mathrm{dL}$ \\
\hline $\mathrm{HbA1C}$ & $\leq 7 \%, 32 \rightarrow 52 \%$ & Mean, $8.3 \rightarrow 7.5 \%$ & Mean, $6.7 \rightarrow 6.2 \%$ \\
\hline
\end{tabular}

ASA, aspirin; AMM, aggressive medical management; MRA. Magnetic resonance angiography.

Table 2. Risk factors associated with ICAD

\begin{tabular}{|c|c|c|c|}
\hline Asymptomatic ICAD in stroke-free & Severity of ICAD & Progression of stenosis & Stroke recurrence among symptomatic ICAD \\
\hline Hypertension $66-71$ & Diabetes $^{54}$ & Diabetes $^{73}$ & Systolic BP $\geq 140$ mmHg ${ }^{75}$ \\
\hline Diabetes ${ }^{66,67,68,71}$ & Lipid disorder $^{54}$ & Smoking $^{73}$ & Cholesterol $\geq 200 \mathrm{mg} / \mathrm{dL}^{75}$ \\
\hline Lipid disorder ${ }^{66,71}$ & Metabolic syndrome ${ }^{54,49,51}$ & Absence of carotid disease ${ }^{74}$ & Metabolic syndrome ${ }^{76}$ \\
\hline Metabolic syndrome ${ }^{53}$ & Smoking $^{72}$ & Apolipoprotein B/A1 ratio ${ }^{62}$ & Severe stenosis $\geq 70 \%{ }^{27}$ \\
\hline Age $^{66,67,68,70,71}$ & & & Race $(\text { black })^{77}$ \\
\hline Male ${ }^{67,69}$ & & & Poor collaterals ${ }^{78}$ \\
\hline Race (Asian and black) $)^{69}$ & & & \\
\hline
\end{tabular}


erosclerosis. ${ }^{48-50}$ Because ICAD risk could not be fully explained by conventional risk factors, there have been efforts to find risk factors specific to ICAD.

Controversial results regarding risk factors for ICAD could be caused by the following reasons. First, the current stroke classification system may have limitations in defining ICAD. We have recently reported that $\mathrm{BOD}$-type $\mathrm{ICAD}$ patients were frequently misclassified as having $\mathrm{SAD}$ or cryptogenic stroke under the TOAST or revised (SSS) TOAST classification. ${ }^{33}$ Second, as mentioned earlier, various mechanisms of stroke exist related to ICAD (Figure 1), and the risk factors may differ depending on the stroke mechanisms. Lastly, there may be nonconventional risk factors for ICAD. Metabolic syndrome is a cluster of cardiovascular disease risk factors and metabolic alterations associated with excess fat. We have previously reported an association between metabolic syndrome and ICAD. ${ }^{48} \mathrm{~Pa}-$ tients with more severe metabolic abnormalities were more likely to have severe intracranial atherosclerosis but not extracranial atherosclerosis, suggesting a dose-dependent relationship. ${ }^{49,51}$ These results were confirmed by other studies from different cohorts of asymptomatic multi-ethnic populations ${ }^{52,53}$ and symptomatic ICAD patients in a multi-center trial. ${ }^{54} \mathrm{~A}$ recent genetic study also supported this association. ${ }^{55}$ Risk factors, components of metabolic SD, elevated serum insulin, and adipokines secreted from adipocytes, all cause oxidative stress and endothelial dysfunction. ${ }^{56,51,18}$ Adults with the metabolic syndrome have suboptimal concentrations of several antioxidants, and intracranial arteries may become susceptible to oxidative stress. Oxidative stress leads to the attenuation of endothelial function through decreased production of nitric oxide (NO) and increased destruction of NO by superoxide. ${ }^{57}$ The Asymptomatic Intracranial Atherosclerosis (AsIA) study showed that asymmetric-dimethylarginine (ADMA, an endogenous inhibitor of endothelial NO) was associated with ICAD.${ }^{53}$ In addition, a recent report evaluating the circulating endothelial microparticle pattern in stroke patients showed that ICAD and ECAS may have different pathophysiologies. ${ }^{58}$ It was speculated that the endothelial activation is related to plaque instability in patients with extracranial arterial stenosis, and endothelial apoptosis is related to vascular narrowing in patients with ICAD. ${ }^{58}$

\section{Treatment strategies in ICAD: endothelium, plaque, and platelet}

Several treatments could improve endothelial function. The most consistently reported treatment strategies that have restored endothelial function are statins, angiotensin converting enzyme inhibitors, phosphodiesterase inhibitors to enhance
NO signaling (e.g. cilostazol and sildenafil), control of vascular risk factors, and lifestyle modification (exercise and smoking cessation). Several active clinical trials are currently seeking to restore the endothelial dysfunction. In particular, because the use of a high-dose statin reportedly improved arterial elasticity and reduced the plaque burden of carotid and coronary arteries (anti-atherogenic effects), ${ }^{59}$ several clinical trials of statins are ongoing in patients with ICAD. In addition, cilostazol reportedly protects endothelial function ${ }^{60}$ and prevents progression of intracranial stenosis. ${ }^{61} \mathrm{~A}$ recent multicenter clinical trial (the Trial of Cilostazol in Symptomatic Intracranial Arterial Stenosis [TOSS]-2 trial) found no significant difference in the vascular events between cilostazol and clopidogrel therapies in patients with symptomatic ICAD.$^{62}$ In this study, the cilostazol group had a trend toward decreased progression of symptomatic intracranial stenosis and more regression of asymptomatic intracranial stenosis with a reduction in the level of apolipoprotein $\mathrm{B}$, whereas the clopidogrel group showed a tendency toward fewer new lesions. A randomized clinical trial showed that combination therapy with clopidogrel and aspirin is more effective than aspirin alone in reducing microembolic signals in patients with acute symptomatic ICAD. ${ }^{63}$

Therefore, it is possible that therapeutic target differs between hyperacute (platelet) vs. subacute/chronic stages (endothelium and plaque) after stroke in ICAD patients. In addition, treatment effects may differ among the different types of ICAD. For example, the use of aggressive antiplatelet agents and stenting (in selected patients) can be considered in patients with a higher degree of stenosis and non-BOD type infarcts, whereas stenting may be harmful (perforator stroke due to snowplowing effect) in patients with BOD. Strategies targeting anti-atherogenic effects and restoration of endothelial function may be more efficacious in the latter patients.

Last but not least, public health measures may be particularly important in this subtype of stroke. The very recently reported Chinese IntraCranial AtheroSclerosis (CICAS) study showed a geographic and sex difference in the distribution of symptomatic ICAD in China, which may be explained by differences in risk factors such as obesity, alcohol/smoking habit, and diabetes. ${ }^{64}$ In addition, since the Asian population is known to be preferentially affected, focused trials need to be performed to establish treatment modalities that are most effective in this population. ${ }^{65}$

\section{Summary}

The failure of the major clinical trials of ICAD may be caused by limitations in the current understanding of ICAD. Various 
mechanisms are associated with stroke in patients with ICAD, as compared to those with extracranial carotid stenosis or atrial fibrillation. It is unlikely that one therapeutic strategy (such as stenting of a new device) will succeed in the near future because endothelium/plaque and platelets both play an important role in the development of stroke in patients with ICAD. Treatment strategies might be selected based on clinical features (including the time after onset) and serologic and neuroimaging biomarkers (including DWI pattern, plaque images, and microembolic signals). Although treatment effects may differ among the different types of ICAD, patients with all of these types of ICAD were included together in clinical trials of ICAD. Selection of target patients based on the ICAD types is needed in clinical trials of ICAD. In addition, recently developed MRI techniques (e.g. plaque image) and results of novel biomarkers (e.g. endothelial dysfunction) may extend our understanding of pathophysiological mechanisms of stroke in patients with ICAD. Further clinical trials using serologic and neuroimaging biomarkers as surrogate biomarkers would save time and money.

\section{References}

1. Amarenco P, Bogousslavsky J, Callahan A 3rd, Goldstein LB, Hennerici M, Rudolph AE, et al. High-dose atorvastatin after stroke or transient ischemic attack. N Engl J Med 2006;355:549559.

2. Furie KL, Kasner SE, Adams RJ, Albers GW, Bush RL, Fagan SC, et al. Guidelines for the prevention of stroke in patients with stroke or transient ischemic attack: a guideline for healthcare professionals from the american heart association/american stroke association. Stroke 2011;42:227-276.

3. Lee PH, Oh SH, Bang OY, Joo SY, Joo IS, Huh K. Infarct patterns in atherosclerotic middle cerebral artery versus internal carotid artery disease. Neurology 2004;62:1291-1296.

4. Shin DH, Lee PH, Bang OY. Mechanisms of recurrence in subtypes of ischemic stroke: a hospital-based follow-up study. Arch Neurol 2005;62:1232-1237.

5. Bang OY, Lee PH, Yoon SR, Lee MA, Joo IS, Huh K. Inflammatory markers, rather than conventional risk factors, are different between carotid and mca atherosclerosis. J Neurol Neurosurg Psychiatry 2005;76:1128-1134.

6. Chimowitz MI, Lynn MJ, Howlett-Smith H, Stern BJ, Hertzberg VS, Frankel MR, et al. Comparison of warfarin and aspirin for symptomatic intracranial arterial stenosis. $N$ Engl J Med 2005;352:1305-1316.

7. Chimowitz MI, Lynn MJ, Derdeyn CP, Turan TN, Fiorella D, Lane BF, et al. Stenting versus aggressive medical therapy for intracranial arterial stenosis. N Engl J Med 2011;365:993-1003.
8. Qureshi AI, Feldmann E, Gomez CR, Johnston SC, Kasner SE, Quick DC, et al. Intracranial atherosclerotic disease: an update. Ann Neurol 2009;66:730-738.

9. Bos D, van der Rijk MJ, Geeraedts TE, Hofman A, Krestin GP, Witteman JC, et al. Intracranial carotid artery atherosclerosis: prevalence and risk factors in the general population. Stroke 2012; 43:1878-1884.

10. Wong KS, Ng PW, Tang A, Liu R, Yeung V, Tomlinson B. Prevalence of asymptomatic intracranial atherosclerosis in high-risk patients. Neurology 2007;68:2035-2038.

11. Wong LK. Global burden of intracranial atherosclerosis. Int $J$ Stroke 2006;1:158-159.

12. Sacco RL, Kargman DE, Zamanillo MC. Race-ethnic differences in stroke risk factors among hospitalized patients with cerebral infarction: the Northern Manhattan Stroke Study. Neurology 1995;45:659-663.

13. Gorelick PB, Wong KS, Bae HJ, Pandey DK. Large artery intracranial occlusive disease: a large worldwide burden but a relatively neglected frontier. Stroke 2008;39:2396-2399.

14. Mak W, Cheng TS, Chan KH, Cheung RT, Ho SL. A possible explanation for the racial difference in distribution of large-arterial cerebrovascular disease: ancestral european settlers evolved genetic resistance to atherosclerosis, but confined to the intracranial arteries. Medical Hypotheses 2005;65:637-648.

15. Sacco RL, Kargman DE, Gu Q, Zamanillo MC. Race-ethnicity and determinants of intracranial atherosclerotic cerebral infarction. The Northern Manhattan Stroke Study. Stroke 1995;26: 14-20.

16. Forouhi NG, Sattar N. Cvd risk factors and ethnicity--a homogeneous relationship? Atheroscler Suppl 2006;7:11-19.

17. Boden-Albala B, Sacco RL, Lee HS, Grahame-Clarke C, Rundek T, Elkind MV, et al. Metabolic syndrome and ischemic stroke risk: Northern Manhattan Study. Stroke 2008;39:30-35.

18. Bang OY, Saver JL, Liebeskind DS, Pineda S, Yun SW, Ovbiagele B. Impact of metabolic syndrome on distribution of cervicocephalic atherosclerosis: data from a diverse race-ethnic group. J Neurol Sci 2009;284:40-45.

19. Hachinski V. Stroke in Korean. Stroke 2008;39:1067.

20. Jung KH, Lee SH, Kim BJ, Yu KH, Hong KS, Lee BC, et al. Secular trends in ischemic stroke characteristics in a rapidly developed country: results from the Korean Stroke Registry Study (secular trends in Korean stroke). Circ Cardiovasc Qual Outcomes 2012;5:327-334.

21. Kamada F, Aoki Y, Narisawa A, Abe Y, Komatsuzaki S, Kikuchi A, et al. A genome-wide association study identifies RNF213 as the first Moyamoya disease gene. J Hum Genet 2011;56:3440.

22. Liu W, Morito D, Takashima S, Mineharu Y, Kobayashi H, Hi- 
tomi T, et al. Identification of RNF213 as a susceptibility gene for moyamoya disease and its possible role in vascular development. PLoS One 2011;6:e22542.

23. Liu W, Hashikata H, Inoue K, Matsuura N, Mineharu Y, Kobayashi $\mathrm{H}$, et al. A rare Asian founder polymorphism of Raptor may explain the high prevalence of Moyamoya disease among East Asians and its low prevalence among Caucasians. Environ Health Prev Med 2010;15:94-104.

24. Liu W, Hitomi T, Kobayashi H, Harada KH, Koizumi A. Distribution of Moyamoya disease susceptibility polymorphism p.R4810K in RNF213 in East and Southeast Asian populations. Neurol Med Chir 2012;52:299-303.

25. Im SH, Cho CB, Joo WI, Chough CK, Park HK, Lee KJ, et al. Prevalence and epidemiological features of moyamoya disease in Korea. J Cerebrovasc Endovasc Neurosurg 2012;14:75-78.

26. Mazighi M, Tanasescu R, Ducrocq X, Vicaut E, Bracard S, Houdart E, et al. Prospective study of symptomatic atherothrombotic intracranial stenoses: the GESICA study. Neurology 2006;66: 1187-1191.

27. Kasner SE, Chimowitz MI, Lynn MJ, Howlett-Smith H, Stern BJ, Hertzberg VS, et al. Predictors of ischemic stroke in the territory of a symptomatic intracranial arterial stenosis. Circulation 2006;113:555-563.

28. Arenillas JF, Molina CA, Montaner J, Abilleira S, GonzalezSanchez MA, Alvarez-Sabin J. Progression and clinical recurrence of symptomatic middle cerebral artery stenosis: a longterm follow-up transcranial Doppler ultrasound study. Stroke 2001;32:2898-2904.

29. Wong KS, Li H, Lam WW, Chan YL, Kay R. Progression of middle cerebral artery occlusive disease and its relationship with further vascular events after stroke. Stroke 2002;33:532-536.

30. Jung JM, Kang DW, Yu KH, Koo JS, Lee JH, Park JM, et al. Predictors of recurrent stroke in patients with symptomatic intracranial arterial stenosis. Stroke 2012;43:2785-2787.

31. Wong KS, Gao S, Chan YL, Hansberg T, Lam WW, Droste DW, et al. Mechanisms of acute cerebral infarctions in patients with middle cerebral artery stenosis: a diffusion-weighted imaging and microemboli monitoring study. Ann Neurol 2002;52:7481 .

32. Bang OY, Heo JH, Kim JY, Park JH, Huh K. Middle cerebral artery stenosis is a major clinical determinant in striatocapsular small, deep infarction. Arch Neurol 2002;59:259-263.

33. Ryoo S, Park JH, Kim SJ, Kim GM, Chung CS, Lee KH, et al. Branch occlusive disease: clinical and magnetic resonance angiography findings. Neurology 2012;78:888-896.

34. Nah HW, Kang DW, Kwon SU, Kim JS. Diversity of single small subcortical infarctions according to infarct location and parent artery disease: analysis of indicators for small vessel dis- ease and atherosclerosis. Stroke 2010;41:2822-2827.

35. Gomez CR, Qureshi AI. Medical treatment of patients with intracranial atherosclerotic disease. J Neuroimaging 2009;19 Suppl 1:25S-29S.

36. Mazighi M, Labreuche J, Gongora-Rivera F, Duyckaerts C, Hauw JJ, Amarenco P. Autopsy prevalence of intracranial atherosclerosis in patients with fatal stroke. Stroke 2008;39:11421147.

37. Xu WH, Li ML, Gao S, Ni J, Zhou LX, Yao M, et al. In vivo highresolution MR imaging of symptomatic and asymptomatic middle cerebral artery atherosclerotic stenosis. Atherosclerosis 2010; 212:507-511.

38. Skarpathiotakis M, Mandell DM, Swartz RH, Tomlinson G, Mikulis DJ. Intracranial atherosclerotic plaque enhancement in patients with ischemic stroke. AJNR Am J Neuroradiol 2013; 34:299-304.

39. Kim JM, Jung KH, Sohn CH, Moon J, Han MH, Roh JK. Middle cerebral artery plaque and prediction of the infarction pattern. Arch Neurol 2012;69:1470-1475.

40. Xu WH, Li ML, Gao S, Ni J, Zhou LX, Yao M, et al. Plaque distribution of stenotic middle cerebral artery and its clinical relevance. Stroke 2011;42:2957-2959.

41. Yoon Y, Lee DH, Kang DW, Kwon SU, Kim JS. Single subcortical infarction and atherosclerotic plaques in the middle cerebral artery: high-resolution magnetic resonance imaging findings. Stroke 2013;44:2462-2467.

42. Wong KS, Chen C, Ng PW, Tsoi TH, Li HL, Fong WC, et al. Low-molecular-weight heparin compared with aspirin for the treatment of acute ischaemic stroke in asian patients with large artery occlusive disease: a randomised study. Lancet Neurol 2007;6:407-413.

43. Whiteley WN, Adams HP Jr, Bath PM, Berge E, Sandset PM, Dennis M, et al. Targeted use of heparin, heparinoids, or lowmolecular-weight heparin to improve outcome after acute ischaemic stroke: an individual patient data meta-analysis of randomised controlled trials. Lancet Neurol 2013;12:539-545.

44. Turan TN, Derdeyn CP, Fiorella D, Chimowitz MI. Treatment of atherosclerotic intracranial arterial stenosis. Stroke 2009;40: 2257-2261.

45. Abou-Chebl A, Steinmetz H. Critique of "Stenting versus aggressive medical therapy for intracranial arterial stenosis" by Chimowitz et al in the new England Journal of Medicine. Stroke 2012;43:616-620.

46. Marks MP. Is there a future for endovascular treatment of intracranial atherosclerotic disease after stenting and aggressive medical management for preventing recurrent stroke and intracranial stenosis (SAMMPRIS)? Stroke 2012;43:580-584.

47. Marquardt L, Geraghty OC, Mehta Z, Rothwell PM. Low risk 
of ipsilateral stroke in patients with asymptomatic carotid stenosis on best medical treatment: a prospective, populationbased study. Stroke 2010;41:e11-17.

48. Bang OY, Kim JW, Lee JH, Lee MA, Lee PH, Joo IS, et al. Association of the metabolic syndrome with intracranial atherosclerotic stroke. Neurology 2005;65:296-298.

49. Park JH, Kwon HM, Roh JK. Metabolic syndrome is more associated with intracranial atherosclerosis than extracranial atherosclerosis. Eur J Neurol 2007; 14:379-386.

50. Kim YD, Choi HY, Jung YH, Nam CM, Yang JH, Cho HJ, et al. Classic risk factors for atherosclerosis are not major determinants for location of extracranial or intracranial cerebral atherosclerosis. Neuroepidemiology 2009;32:201-207.

51. Bang OY, Saver JL, Ovbiagele B, Choi YJ, Yoon SR, Lee KH. Adiponectin levels in patients with intracranial atherosclerosis. Neurology 2007;68:1931-1937.

52. Rincon F, Sacco RL, Kranwinkel G, Xu Q, Paik MC, BodenAlbala B, et al. Incidence and risk factors of intracranial atherosclerotic stroke: the Northern Manhattan Stroke Study. Cerebrovasc Dis 2009;28:65-71.

53. Lopez-Cancio E, Galan A, Dorado L, Jimenez M, Hernandez M, Millan M, et al. Biological signatures of asymptomatic extra- and intracranial atherosclerosis: the Barcelona-Asia (Asymptomatic Intracranial Atherosclerosis) study. Stroke 2012;43:27122719.

54. Turan TN, Makki AA, Tsappidi S, Cotsonis G, Lynn MJ, Cloft $\mathrm{HJ}$, et al. Risk factors associated with severity and location of intracranial arterial stenosis. Stroke 2010;41:1636-1640.

55. Yamada Y, Kato K, Oguri M, Yoshida T, Yokoi K, Watanabe S, et al. Association of genetic variants with atherothrombotic cerebral infarction in Japanese individuals with metabolic syndrome. Int J Mol Med 2008;21:801-808.

56. Bang OY. Intracranial atherosclerotic stroke: specific focus on the metabolic syndrome and inflammation. Curr Atheroscler Rep 2006;8:330-336.

57. Anderson TJ. Assessment and treatment of endothelial dysfunction in humans. JAm Coll Cardiol 1999;34:631-638.

58. Jung KH, Chu K, Lee ST, Park HK, Bahn JJ, Kim DH, et al. Circulating endothelial microparticles as a marker of cerebrovascular disease. Ann Neurol 2009;66:191-199.

59. Ratchford EV, Gutierrez J, Lorenzo D, McClendon MS, DellaMorte D, DeRosa JT, et al. Short-term effect of atorvastatin on carotid artery elasticity: a pilot study. Stroke 2011;42:34603464.

60. Oyama N, Yagita Y, Kawamura M, Sugiyama Y, Terasaki Y, Omura-Matsuoka E, et al. Cilostazol, not aspirin, reduces ischemic brain injury via endothelial protection in spontaneously hypertensive rats. Stroke 2011;42:2571-2577.
61. Kwon SU, Cho YJ, Koo JS, Bae HJ, Lee YS, Hong KS, et al. Cilostazol prevents the progression of the symptomatic intracranial arterial stenosis: the multicenter double-blind placebocontrolled trial of cilostazol in symptomatic intracranial arterial stenosis. Stroke 2005;36:782-786.

62. Kwon SU, Hong KS, Kang DW, Park JM, Lee JH, Cho YJ, et al. Efficacy and safety of combination antiplatelet therapies in patients with symptomatic intracranial atherosclerotic stenosis. Stroke 2011;42:2883-2890.

63. Wong KS, Chen C, Fu J, Chang HM, Suwanwela NC, Huang $\mathrm{YN}$, et al. Clopidogrel plus aspirin versus aspirin alone for reducing embolisation in patients with acute symptomatic cerebral or carotid artery stenosis (CLAIR study): a randomised, open-label, blinded-endpoint trial. Lancet Neurol 2010;9:489497.

64. Pu Y, Liu L, Wang Y, Zou X, Pan Y, Soo Y, et al. Geographic and sex difference in the distribution of intracranial atherosclerosis in china. Stroke 2013;44:2109-2114.

65. Khan M, Naqvi I, Bansari A, Kamal AK. Intracranial atherosclerotic disease. Stroke Res Treat 2011;2011:282845.

66. Wong KS, Huang YN, Yang HB, Gao S, Li H, Liu JY, et al. A door-to-door survey of intracranial atherosclerosis in Liangbei County, China. Neurology 2007;68:2031-2034.

67. Huang HW, Guo MH, Lin RJ, Chen YL, Luo Q, Zhang Y, et al. Prevalence and risk factors of middle cerebral artery stenosis in asymptomatic residents in Rongqi County, Guangdong. Cerebrovasc Dis 2007;24:111-115.

68. Bae HJ, Lee J, Park JM, Kwon O, Koo JS, Kim BK, et al. Risk factors of intracranial cerebral atherosclerosis among asymptomatics. Cerebrovasc Dis 2007;24:355-360.

69. Moossy J. Pathology of cerebral atherosclerosis. Influence of age, race, and gender. Stroke 1993;24(Suppl 12):I22-23; I31-22.

70. Park KY, Chung CS, Lee KH, Kim GM, Kim YB, Oh K. Prevalence and risk factors of intracranial atherosclerosis in an asymptomatic Korean population. J Clin Neurol 2006;2:29-33.

71. Uehara T, Tabuchi M, Mori E. Risk factors for occlusive lesions of intracranial arteries in stroke-free Japanese. Eur J Neurol 2005; 12:218-222.

72. Kim DE, Lee KB, Jang IM, Roh H, Ahn MY, Lee J. Associations of cigarette smoking with intracranial atherosclerosis in the patients with acute ischemic stroke. Clin Neurol Neurosurg 2012;114:1243-1247.

73. Miyazawa N, Akiyama I, Yamagata Z. Analysis of incidence and risk factors for progression in patients with intracranial steno-occlusive lesions by serial magnetic resonance angiography. Clin Neurol Neurosurg 2007; 109:680-685.

74. Akins PT, Pilgram TK, Cross DT 3rd, Moran CJ. Natural history of stenosis from intracranial atherosclerosis by serial angi- 
ography. Stroke 1998;29:433-438.

75. Chaturvedi S, Turan TN, Lynn MJ, Kasner SE, Romano J, Cotsonis $\mathrm{G}$, et al. Risk factor status and vascular events in patients with symptomatic intracranial stenosis. Neurology 2007;69:20632068.

76. Ovbiagele B, Saver JL, Lynn MJ, Chimowitz M. Impact of metabolic syndrome on prognosis of symptomatic intracranial atherostenosis. Neurology 2006;66:1344-1349.
77. Waddy SP, Cotsonis G, Lynn MJ, Frankel MR, Chaturvedi S, Williams JE, et al. Racial differences in vascular risk factors and outcomes of patients with intracranial atherosclerotic arterial stenosis. Stroke 2009;40:719-725.

78. Liebeskind DS, Cotsonis GA, Saver JL, Lynn MJ, Turan TN, Cloft HJ, et al. Collaterals dramatically alter stroke risk in intracranial atherosclerosis. Ann Neurol 2011;69:963-974. 